\title{
The feasibility of a fiber optic laser approach to relieving lymphedematous syndrome:
}

\section{a case report}

Beniamino Palmieri ${ }^{1,2}$

Alessandro Di Cerbo ${ }^{1,2}$

Valentina Rottigni ${ }^{1,2}$

Gregorio Fistetto ${ }^{2}$

Tommaso lannitti ${ }^{2,3}$

'University of Modena, Department of General Surgery and Surgical Specialties, ${ }^{2}$ Poliambulatorio del Secondo Parere, Modena, Italy; ${ }^{3}$ University of Kentucky, Department of Physiology, Lexington, KY, USA

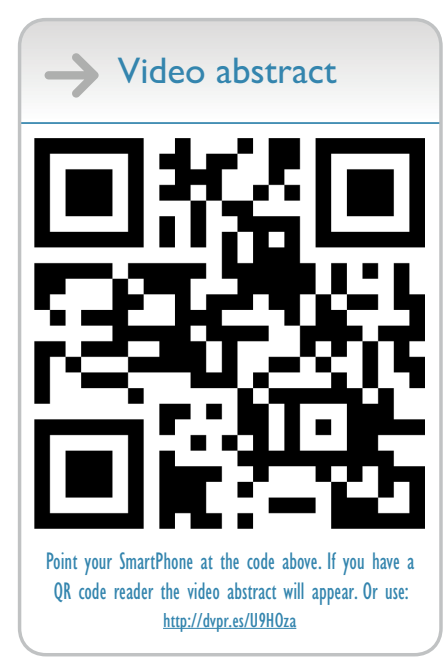

Correspondence: Tommaso lannitti Department of Physiology, School of Medicine, University of Kentucky Medical Center, Lexington,

KY 40536-0298, USA

Tel +39328 28I3314

Email tommaso.iannitti@gmail.com
This article was published in the following Dove Press journal:

OncoTargets and Therapy

8 February 2013

Number of times this article has been viewed

\begin{abstract}
Here we report a case of successful fiber optic laser treatment of lymphedema in a swollen arm post mastectomy. At the moment, this procedure has only anecdotal evidence to justify its use, but in our experience is a feasible, minimally invasive day-stay procedure which has been demonstrated to be safe and effective. Further nonhomogeneous case pooling and follow-up would enable guidelines and definite surgical protocols for its use to be implemented.
\end{abstract}

Keywords: fiber optic, lymphedema, Nd:YAG, laser, mastectomy

\section{Introduction}

Fiber optic laser surgery has been successfully introduced in several medical fields, especially in the oncological area. ${ }^{1-5}$ In angiology, intravenous laser therapy is a dedicated venous procedure which can be used to remove an occlusion in the lumen of the saphenous system. ${ }^{6}$ Over the last 3 years, we have gained considerable confidence in fiber optic technology, and have recently started to use this technique to assist in drainage of interstitial fluid to prevent fibrosis in patients with breast-cancer-related lymphedema. ${ }^{7}$ Furthermore, a previous study used gallium arsenide (GaAs) laser therapy in postmastectomy patients, resulting in limb volume reduction and increases in shoulder mobility and grip strength. ${ }^{8}$ Keeping the fiber optic laser positioned in a $150 \mu \mathrm{m}$ cavity under the skin, the laser is then rotated upwards and activated to produce a series of short radial 10-15 cm tunnels within the normal lymphatic network in the skin, with the aim of diverting the volume of pooled interstitial fluid cephalad, redistributing the fluid in different directions by pressotherapy, ${ }^{9}$ and inducing reabsorption of the fluid into the lymphatic vessels (Figure 1). The procedure can be performed under local anesthesia with or without simple sedation, and with the aid of a skin cooling system. ${ }^{10}$ Because it is an office or day-surgery procedure, it should not require any theatre time or prolonged hospital stay.

\section{Case report}

Twelve months ago, a 77-year-old woman, who had had a partial right mastectomy (biquadrantectomy) and lymphadenectomy for metastatic cancer, presented with progressive lymphedema of her right arm and an erysipelatous infection which was immediately treated with an aggressive combination regimen of teicoplanin (Targosid, $200 \mathrm{mg}$; Sanofi-Aventis, Milan, Italy) and vancomycin (Vancomicina Hikma, 250 mg; Hikma Italia, Pavia, Italy). The patient underwent rehabilitation consisting of overnight elastic support with regular active and passive muscle exercise during the day. The patient's arm 


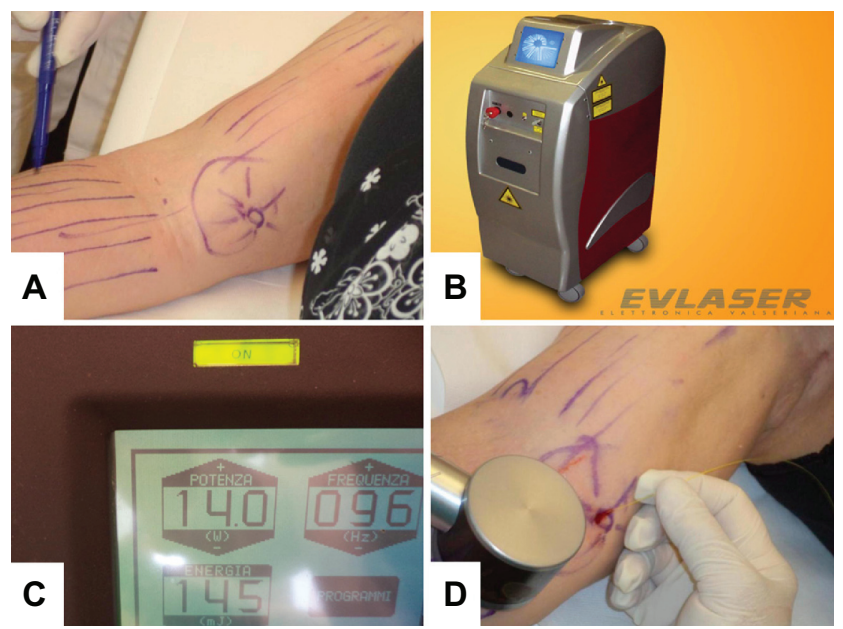

Figure I (A) Radial short tunnels along the right upper arm. (B and C) Nd:YAG laser device and operating settings. (D) Introduction of the fiber optic laser through an incision in the skin, along with the skin cooling system.

circumference measurements at presentation are reported in Table 1. The patient signed an informed consent explaining the laser procedure in detail and its potential complications. She agreed to undergo laser treatment in view of progressive hardening and stiffening of her finger, wrist, and elbow. The procedure was performed in accordance with the tenets of the Declaration of Helsinki. Internal review board approval was obtained.

A $1062 \mathrm{~nm} 15 \mathrm{~W}$ Nd:YAG system (Evlaser ${ }^{\circledR}$, Elettronica Valseriana, Casnigo, Italy) was used. It was connected to a $150 \mu \mathrm{m}$ diameter and $1 \mathrm{~m}$ long sterile fiber optic. Tramadol (Unitrama, $100 \mathrm{mg}$ capsules; Angelini, Rome, Italy) and ketoprofen (Artrosilene, $160 \mathrm{mg} / 2 \mathrm{~mL}$ injectable solution; Dompé, L'Aquila, Italy) were administered by an intravenous line at the beginning of treatment, with an assistant cooling the arm using a frozen $10 \mathrm{~cm}^{2}$ diameter plate. A bolus of $2 \%$ lidocaine (Lidocaina $100 \mathrm{mg} / 5 \mathrm{~mL}$; Angelini) was injected to anesthetize the $2 \mathrm{~cm}^{2}$ area of skin selected to introduce the fiber optic laser. Skin perforation was performed using a 21-gauge plastic venous catheter bearing a stainless steel stylet to aid introduction. Next, the stylet was withdrawn and the fiber optic laser was introduced into the lumen and advanced forward with its tip continuously emitting $150 \mathrm{~J} / \mathrm{cm}^{2}$ to perforate the fibrous tissue and create a channel during advancement along the entire length of her arm (Figure 2). At the end of the procedure, the fiber optic tip was retrieved via the incision in the skin and redirected subdermally upwards into the normal lymphatic network, advanced for a shorter length $(15-20 \mathrm{~cm})$ in multiple radial directions to create shorter (15-30) tunnels where the lymph, which had been pushed upwards, could be temporarily pooled and then absorbed via the normal lymphatic network. The time taken to complete the procedure was about 1.5 hours. No stitches were required at the laser access site, and an elastic bandage was applied for 24 hours postoperatively. At 10-day follow-up, a decrease of arm and forearm circumference was observed (Figure 3; Table 1). The procedure was repeated 2 weeks later in previously untreated regions of her right arm using the same protocol to achieve further volume reduction (Figure 3) and thereby improve her arm function. After the second session, the patient's range of movement at her fingers, wrist, and elbow had improved.

Four month follow-up showed partial relapse of the treated segments consistent with hardness and stiffness. No further decrease in right arm circumference was observed, but the patient did not revert to her original clinical condition and asked for a third laser procedure because of the pain-free nature and low invasiveness of the method. After the procedure, the patient underwent three daily 30-minute sessions of manual lymph drainage and home pressotherapy twice daily for a week.

\section{Discussion}

This is the first report of the feasibility and safety of a novel procedure to reduce lymphedema using fiber optic laser to drill new channels for lymphatic drainage. In our experience, the procedure can be repeated up to 5-10 times in 6 months, depending on the patient's connective tissue reaction. Lymph drainage by manual massage and pressotherapy helps the drilled tunnels to become engorged with interstitial fluid and improves their patency, which counteracts occlusion by exceeding the outer-inner pressure ratio. The procedure described in this article is painless, if local anesthesia is

Table I Patient's upper limb circumference measurements before and after first and second treatment

\begin{tabular}{|c|c|c|c|c|c|c|}
\hline & Right arm & Left arm & Right forearm & Left forearm & Right wrist & Left wrist \\
\hline First treatment & $36 \mathrm{~cm}$ & $30 \mathrm{~cm}$ & $33 \mathrm{~cm}$ & $26 \mathrm{~cm}$ & $22 \mathrm{~cm}$ & $19 \mathrm{~cm}$ \\
\hline First follow-up ( 10 days) & $34 \mathrm{~cm}$ & $30 \mathrm{~cm}$ & $31 \mathrm{~cm}$ & $26 \mathrm{~cm}$ & $22 \mathrm{~cm}$ & $19 \mathrm{~cm}$ \\
\hline Second treatment & $34 \mathrm{~cm}$ & $30 \mathrm{~cm}$ & $31 \mathrm{~cm}$ & $26 \mathrm{~cm}$ & $20 \mathrm{~cm}$ & $19 \mathrm{~cm}$ \\
\hline \multicolumn{2}{|c|}{ Second follow-up (4 months) $34 \mathrm{~cm}$} & $30 \mathrm{~cm}$ & $30 \mathrm{~cm}$ & $26 \mathrm{~cm}$ & $20 \mathrm{~cm}$ & $19 \mathrm{~cm}$ \\
\hline
\end{tabular}

Note: Partial relapse of treated segments observed after second follow-up. 


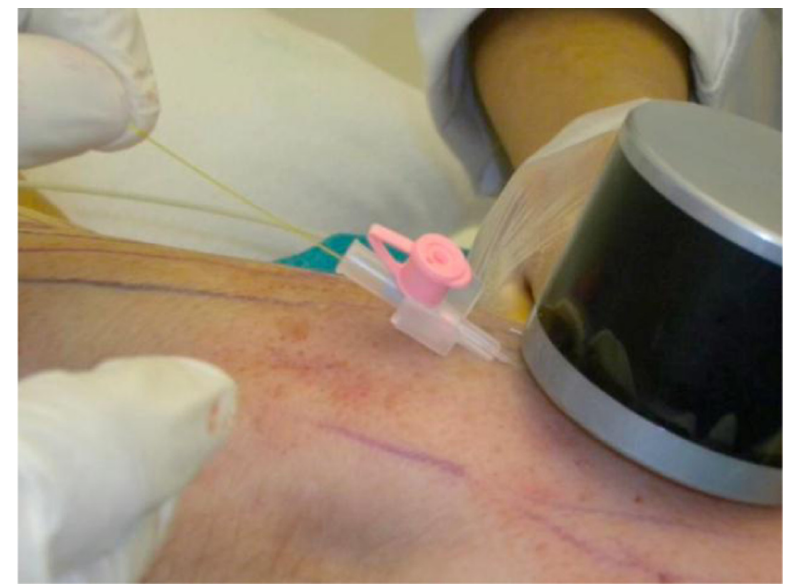

Figure 2 Introduction of a 21 -gauge plastic venous catheter and subsequently of the fiber optic laser through an incision in the skin.

used at the skin access site and the arm surface is regularly cooled. ${ }^{11}$ Obviously, multiple longitudinal channel drilling cannot be considered a radical management procedure for lymphedema. Because it achieves autonomous active lymphatic drainage, regular daily mechanical or manual pressotherapy ${ }^{9}$ is required to keep the channels open and prevent further fibrotic reactions and obstruction of continuous lymph flow into the newly formed lumen. In our experience, it is mandatory to prepare a functional area in the normal dermis cephalad to the lymphedematous tissue in order to distribute the drained lymphatic volume recovered by daily pressotherapy through these short $(15-20 \mathrm{~cm})$ newly formed channels. Even if this step may damage the normal lymphatic network in the adjacent area, ${ }^{12}$ it is necessary in order to facilitate uptake of fluid into normal lymphatic vessels. In

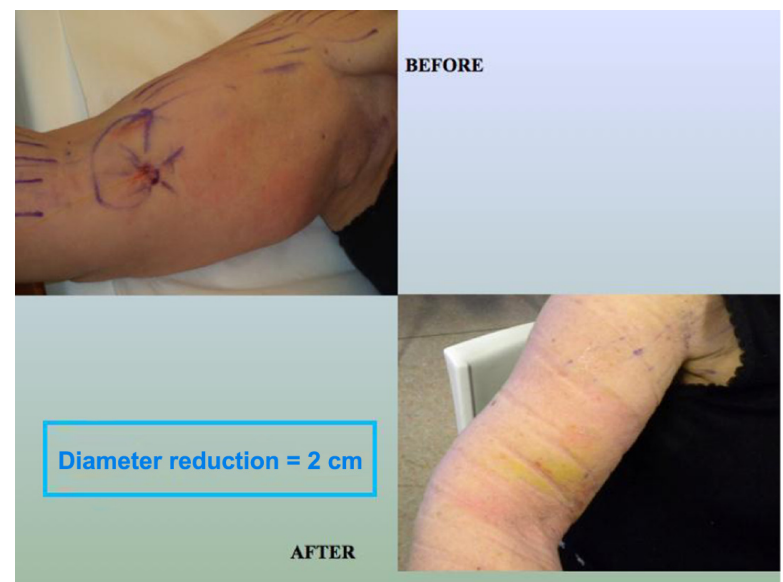

Figure 3 Two-cm reduction in right arm circumference after first treatment with $\mathrm{Nd}$ :YAG $1062 \mathrm{~nm}$ (I5 W) endovenous laser.

Note: "Diameter" refers to right arm circumference diameter. fact, in our experience, it is very easy to drill the fibrotic septa that trap interstitial fluid in lymphedema by laser energy, but these passive newly formed lumina are prone to further fibrosis and obliteration. Therefore, our future goal will be to seed a layer of autologous endothelial cells recovered from short-segment phlebectomy into the newly formed channels or inject bone marrow-derived mesothelial stem cells to form a new endothelial surface, mimicking the patency and function of the normal lymphatic network. ${ }^{13}$ Our fiber optic laser channel drilling approach with moderate beam power $\left(150 \mathrm{~J} / \mathrm{cm}^{2}\right)$ is very effective for rapid perforation of fibrous strands of lymphedematous tissue, without excessive heating or burning adjacent structures. In particular, when the fiber optic is withdrawn at the end of treatment, the interstitial fluid becomes cooler quickly since it is forced to diffuse into the new channels created by the laser. Active and passive rehabilitation exercise promotes continuous lymph flow into these structures, prolongs their patency and viability, and may be very efficacious if antifibrotic treatment is administered at the same time. ${ }^{14}$

\section{Conclusion}

Treatment of lymphedema using fiber optic laser is now a promising candidate treatment for helping pressotherapy rehabilitation to improve function and quality of life in patients affected by lymphedema.

\section{Disclosure}

The authors report no conflict of interest with any financial organization regarding the material discussed in the paper.

\section{References}

1. Fahy AK, Waldow SM. Evaluation of changes in oxygen tension as indicators of rif-1 tumor response to Nd:YAG laser heating. Lasers Surg Med. 1993;13:312-320.

2. Palmieri B. Terapie Palliative in Oncologia. L'utilizzo di Tecniche Sub-Invasive [Palliative Therapies in Oncology. The Use of Sub-Invasive Techniques]. Milano, Italy; Tecniche Nuove; 2012. Italian.

3. Palmieri B, Iannitti T, Fistetto G, Rottigni V. The "Swiss-cheese Dopplerguided laser tonsillectomy": a new safe cribriform approach to intracapsular tonsillectomy. Lasers Med Sci. August 2, 2012. [Epub ahead of print.]

4. Sanna S, Monteverde M, Taurchini M, Dell'Amore D, Palmieri B, Rottigni V. Lung metastases: update of treatment with Nd:YAG laser 1318 nm. Eur J Oncol. 2011;16:233-240.

5. Shires CB, Shete MM, Thompson JW. Management of suprastomal tracheal fibroma: introduction of a new technique and comparison with other techniques. Int J Pediatr Otorhinolaryngol. 2009;73:67-72.

6. Šikovec A. The treatment of saphenous vein occlusion by endovenous laser ablation (EVLA) with a $1064 \mathrm{~nm}$ VSP Nd:YAG laser. Journal of the Laser and Health Academy. 2009;1:1-5.

7. Dirican A, Andacoglu O, Johnson R, McGuire K, Mager L, Soran A. The short-term effects of low-level laser therapy in the management of breastcancer-related lymphedema. Support Care Cancer. 2011;19:685-690. 
8. Ahmed Omar MT, Abd-El-Gayed Ebid A, El Morsy AM. Treatment of post-mastectomy lymphedema with laser therapy: double blind placebo control randomized study. J Surg Res. 2011;165:82-90.

9. Leduc O, Leduc A. Rehabilitation protocol in upper limb lymphedema. Ann Ital Chir. 2002;73:479-484.

10. Luo H, Fishbein MC, Bar-Cohen Y, et al. Cooling system permits effective transcutaneous ultrasound clot lysis in vivo without skin damage. J Thromb Thrombolysis. 1998;6:125-131.

11. Ergenoglu MU, Sayin MM, Kucukaksu DS. Endovenous laser ablation with 980-nm diode laser: early and midterm results. Photomed Laser Surg. 2011;29:691-697.
12. Walsh JT Jr, Flotte TJ, Deutsch TF. Er:YAG laser ablation of tissue: effect of pulse duration and tissue type on thermal damage. Lasers Surg Med. 1989;9:314-326.

13. Seebach C, Henrich D, Wilhelm K, Barker JH, Marzi I. Endothelial progenitor cells improve directly and indirectly early vascularization of mesenchymal stem cell-driven bone regeneration in a critical bone defect in rats. Cell Transplant. 2012;21:1667-1677.

14. Choi I, Lee S, Kyoung Chung $\mathrm{H}$, et al. 9-cis retinoic acid promotes lymphangiogenesis and enhances lymphatic vessel regeneration: therapeutic implications of 9-cis retinoic acid for secondary lymphedema. Circulation. 2012;125:872-882.

\section{Publish your work in this journal}

OncoTargets and Therapy is an international, peer-reviewed, open access journal focusing on the pathological basis of all cancers, potential targets for therapy and treatment protocols employed to improve the management of cancer patients. The journal also focuses on the impact of management programs and new therapeutic agents and protocols on

\section{Dovepress}

patient perspectives such as quality of life, adherence and satisfaction The manuscript management system is completely online and includes a very quick and fair peer-review system, which is all easy to use. Visit http://www.dovepress.com/testimonials.php to read real quotes from published authors.

Submit your manuscript here: http://www.dovepress.com/oncotargets-and-therapy-journal 